\title{
Roughness Length of Water Vapor over Land Surfaces and Its Influence on Latent Heat Flux
}

\author{
Sang-Jong Park ${ }^{1}$, Soon-Ung Park ${ }^{2}$, and Chang-Hoi Ho ${ }^{1, *}$ \\ ${ }^{1}$ School of Earth and Environmental Sciences, Seoul National University, Seoul, Korea \\ ${ }^{2}$ Center for Atmospheric and Environmental Modeling, Seoul, Korea
}

Received 23 March 2009, accepted 13 November 2009

\begin{abstract}
Latent heat flux at the surface is largely dependent on the roughness length for water vapor $\left(\mathrm{z}_{0 \mathrm{q}}\right)$. The determination of $\mathrm{z}_{0 \mathrm{q}}$ is still uncertain because of its multifaceted characteristics of surface properties, atmospheric conditions and insufficient observations. In this study, observed values from the Fluxes Over Snow Surface II field experiment (FLOSS-II) from November 2002 to March 2003 were utilized to estimate $\mathrm{z}_{0 q}$ over various land surfaces: bare soil, snow, and senescent grass. The present results indicate that the estimated $\mathrm{z}_{0 \mathrm{q}}$ over bare soil is much smaller than the roughness length of momentum $\left(\mathrm{z}_{0 \mathrm{~m}}\right)$; thus, the ratio $z_{0 m} / z_{0 q}$ is larger than those of previous studies by a factor of 20 - 150 for the available flow regime of the roughness Reynolds number, $\operatorname{Re}_{*}>0.1$. On the snow surface, the ratio is comparable to a previous estimation for the rough flow $\left(\operatorname{Re}_{*}>1\right)$, but smaller by a factor of $10-50$ as the flow became smooth $\left(\operatorname{Re}_{*}<1\right)$. Using the estimated ratio, an optimal regression equation of $\mathrm{z}_{0 \mathrm{~m}} / \mathrm{z}_{0 q}$ is determined as a function of $\mathrm{Re}_{*}$ for each surface type. The present parameterization of the ratio is found to greatly reduce biases of latent heat flux estimation compared with that estimated by the conventional method, suggesting the usefulness of current parameterization for numerical modeling.
\end{abstract}

Key words: Roughness length, Roughness Reynolds number, Surface layer scheme, Water vapor, FLOSS-II

Citation: Park, S. J., S. U. Park, and C. H. Ho, 2010: Roughness length of water vapor over land surfaces and its influence on latent heat flux. Terr. Atmos. Ocean. Sci., 21, 855-867, doi: 10.3319/TAO.2009.11.13.01(Hy)

\section{INTRODUCTION}

The roughness length denotes the height where a meteorological variable, such as wind speed, temperature, and humidity, is extrapolated down to a "surface" value using the log-profile relationship of the Monin-Obukhov similarity theory (Brutsaert 1975). Because the roughness length is a fundamental parameter in the process of atmosphere-land interaction, an adequate description is required to get an accurate simulation of surface fluxes (Beljaars and Holtslag 1991; Lo 1996; Chen et al. 1997; Chen and Dudhia 2001; Bao et al. 2002; Demuzere et al. 2008). Different specifications of roughness length cause significant changes in the boundary layer temperature and humidity distribution as well as circulation even in regional scale (Kang and Hong 2008). It is well known that the roughness length of momentum $\left(\mathrm{z}_{0 \mathrm{~m}}\right)$ is dependent on the nature of the land surface. In

\footnotetext{
* Corresponding author

E-mail: hoch@cpl.snu.ac.kr
}

addition to the nature of the surface, the roughness lengths for heat $\left(\mathrm{z}_{\mathrm{OT}}\right)$ and moisture $\left(\mathrm{z}_{\mathrm{Oq}}\right)$ are altered by the nature of atmospheric flow (Brutsaert 1975). Consequently, both $\mathrm{z}_{\mathrm{OT}}$ and $\mathrm{z}_{0 \mathrm{q}}$ are parameterized in relation with $\mathrm{z}_{0 \mathrm{~m}}$ in terms of the ratios $\ln \left(\mathrm{z}_{0 \mathrm{~m}} / \mathrm{z}_{\mathrm{OT}}\right)$ and $\ln \left(\mathrm{z}_{0 \mathrm{~m}} / \mathrm{z}_{0 \mathrm{q}}\right)$, which are conventionally denoted as $\mathrm{kB}_{\mathrm{T}}^{-1}$ and $\mathrm{kB}_{\mathrm{q}}{ }^{-1}$, respectively. Here, $\mathrm{k}$ is the von Karman constant and $\mathrm{B}^{-1}$ is a parameter used to represent the interfacial sublayer effect (Brutsaert 1982). The parameters $\mathrm{kB}_{\mathrm{T}}^{-1}$ and $\mathrm{kB}_{\mathrm{q}}^{-1}$ are presented as functions of the roughness Reynolds number $\operatorname{Re}_{*}\left(=\mathrm{z}_{0 \mathrm{~m}} \mathrm{u}_{*} / v\right)$, where $\mathrm{u}_{*}$ is the friction velocity and $v$ is the kinematic viscosity of air.

For heat fluxes, the magnitude and variation of $\mathrm{kB}_{\mathrm{T}}{ }^{-1}$ (i.e., $\mathrm{z}_{\mathrm{OT}}$ ) have been investigated in many studies (Verhoef et al. 1997; Sun 1999; Moriwaki and Kanda 2006; Yang et al. 2008). Also some studies parameterized $\mathrm{z}_{\mathrm{OT}}$ using several factors, such as $\mathrm{Re}_{*}$, solar elevation angle, leaf area index, normalized difference vegetation index, temperature scaling parameter, and soil moisture (Kubota and Sugita 1994; Qualls and Hopson 1998; Lhomme et al. 2000; Kotani and 
Sugita 2005; Yang et al. 2008). However, observational validation of $\mathrm{kB}_{\mathrm{q}}^{-1}$ (i.e., $\mathrm{z}_{0 \mathrm{q}}$ ) has been a moderate success only over the ocean (Zilitinkevich et al. 2001; Fairall et al. 2003; Edson et al. 2004; Vickers and Mahrt 2006); it has been less successful over the land (Andreas 2002; Kotani and Sugita 2005; Moriwaki and Kanda 2006). Therefore, further studies are required to determine $\mathrm{kB}_{\mathrm{q}}{ }^{-1}$ more accurately over various land surfaces.

In this study, we attempted to estimate $\mathrm{z}_{0 \mathrm{q}}$ with the parameterization of $\mathrm{kB}_{\mathrm{q}}{ }^{-1}$ for different types of land surfaces, including bare soil, snow, and senescent-grass with the data obtained from the Fluxes Over Snow Surface II (FLOSS-II) field experiment. The present results provide a more accurate estimation of latent heat flux over land surfaces.

\section{DATA AND PROCESSING}

\subsection{Field Experiment}

The FLOSS-II field experiment was conducted from November 2002 to March 2003 on a flat high altitude area in Colorado, USA. The experiment was comprised of three sites: a grass, sage, and lake site. The grass site was densely covered with senescent long grasses (Fig. 1a), and the sage site was populated by sagebrush (Artemisia tridentata). The lake site located at the northern edge of the lake was influenced by the senescent grass surface when wind blew from north and by the dried lake basin when wind blew from south (Figs. 1b and c). Among the three sites, the sage site was not used because its surface was a mixture of shrubs and bare open soil. During the experimental period, it snowed frequently over the three sites (see Fig. 2a), but the persistence of snow cover was different at each site.

Eddy-correlation sensors of Campbell CSAT sonic anemometers and KH20 Krypton hygrometers ( $2 \mathrm{~m}$ above ground) measured turbulent fluxes of momentum, sensible heat, and water vapor. In addition to these fluxes, mean values of wind, temperature, and humidity were also measured at the same height. Radiative surface temperature was obtained from the longwave radiative flux measured by pyrgeometer at each site. Because the experimental sites are located at high altitude approximately $2475 \mathrm{~m}$ above the mean sea level, at the grass site the average value of atmospheric pressure is $751 \mathrm{hPa}$ and air density is $1 \mathrm{~kg} \mathrm{~m}^{-3}$. The time series of meteorological variables including albedo are displayed in Fig. 2. Daily mean solar radiation was below $150 \mathrm{~W} \mathrm{~m}^{-2}$ until February and increased to about $200 \mathrm{~W} \mathrm{~m}^{-2}$ in March (Fig. 2a). Daily mean wind speed varied between 2 and $8 \mathrm{~m} \mathrm{~s}^{-1}$ (Fig. 2b). Air temperature and surface temperature varied from -30 to $0^{\circ} \mathrm{C}$ until February and rose above $0^{\circ} \mathrm{C}$ in March (Fig. 2c). Albedo at the grass site varied between 0.2 and 0.8 in association with several occurrences of snow and melting, while albedo at the lake site remained about 0.8 until February and then fell below 0.6 (Fig. 2d). Daily mean friction velocity of the grass site was larger than that of the lake site due to rougher surface varying between 0.1 and $0.4 \mathrm{~m} \mathrm{~s}^{-1}$ (Fig. 2e). Daily mean humidity scale showed in general upward evaporation (negative $\mathrm{q}_{*}$ ) since January (Fig. 2f). Daily mean roughness Reynolds number of the grass site was larger than that of the lake site varying between 10 and 200 (Fig. 2g). It is shown that daily mean stability is generally stable (Fig. 2h). More detailed descriptions on the FLOSS-II experiment are found in Mahrt and Vickers (2005).

\subsection{Data Selection and Categorization}

The 5-min data obtained from the National Center for Atmospheric Research (NCAR) Research Technology Facility (http://www.eol.ucar.edu/rtf/projects/FLOSSII/) were averaged into 30-min intervals in the present study (Tsuang 2004). Humidity effect on sonic temperature was corrected for sensible heat flux (Schotanus et al. 1983). For latent heat flux, ultraviolet absorption by oxygen molecule was corrected (Van Dijk et al. 2003) and density fluctuation due to heat flux was corrected according to Webb et al. (Webb et al. 1980). Finally, attenuation of correlation due to sensor separation $(27 \mathrm{~cm})$ was corrected using the cospectral function provided by Horst (2003). The surface energy imbalances at the three sites were up to $30 \%$, which was in the range of reported imbalances (Oncley et al. 2007).

The steady-state test was applied to fluxes to ensure the steady state of the flow (Mauder and Foken 2004). For this, small fluxes and counter-gradient fluxes were excluded in this analysis. The data during snow events were also excluded. Because the target parameter $\mathrm{kB}_{\mathrm{q}}{ }^{-1}$ is obtained from the ratio of $\left(\mathrm{z}_{0 \mathrm{~m}} / \mathrm{z}_{0 \mathrm{q}}\right)$, in an effort to minimize uncertainty in $\mathrm{kB}_{\mathrm{q}}{ }^{-1}$, abnormal $\mathrm{z}_{0 \mathrm{~m}}$ data were excluded based on the distributions of the occurrence frequencies of $\mathrm{z}_{0 \mathrm{~m}}$ on each surface. In the lake site, only the data corresponding to the lake basin, that is, wind directions from 170 to 240 degrees, were used in the analysis.

To understand characteristic features of $\mathrm{z}_{0 q}$ according to surface types, the data were categorized into three surface types: bare soil, snow, and senescent grass. Categorization was done based on the daily mean albedo estimated when the downward solar radiations exceeded $300 \mathrm{~W} \mathrm{~m}^{-2}$. The grass site data and lake site data with an albedo higher than 0.7 were considered as snow surfaces, and grass site data with an albedo lower than 0.25 were categorized as senescent grass surface. The lake site data corresponding to an albedo less than 0.25 were considered to represent bare soil surface. Surface with an albedo between 0.7 and 0.25 could be associated with surface partly covered with snow which is not the focus of the current study. In this way, 10 days from the bare soil surface, 99 days from the snow surface, and 25 days from the senescent grass surface were obtained for the analysis. 


\section{ESTIMATION OF THE ROUGHNESS LENGTH}

\subsection{Roughness Length for Momentum}

The roughness length for momentum $\mathrm{z}_{0 \mathrm{~m}}$ for each surface was estimated using the flux-gradient relationship for wind profile as

$U=\frac{u_{*}}{k}\left[\ln \left(\frac{z-d}{z_{0 m}}\right)-\psi_{m}\left(\frac{z-d}{L}\right)+\psi_{m}\left(\frac{z_{0 m}}{L}\right)\right]$

where $U$ is the wind speed at $2 \mathrm{~m}$ height; $z$, the measurement height; $d$, the zero-plane displacement height; $\psi_{m}$, the stability correction function; and $L$, the Monin-Obukhov length scale. The displacement height $d$ was set to zero in this study because it was assumedly negligible compared to the height $z$. Our preliminary test indicated that the choice of stability function resulted in a minor effect for the estimation of the roughness length. So, the stability functions of Dyer (1974) were used because of their simplicity. The estimated $\mathrm{z}_{0 \mathrm{~m}}$ was examined to determine the typical range of $\mathrm{z}_{0 \mathrm{~m}}$ for each surface and to remove possible additional uncertainty in $\mathrm{kB}_{\mathrm{q}}^{-1}$ caused by abnormal $\mathrm{z}_{0 \mathrm{~m}}$. As shown in Fig. 3, the estimated $\mathrm{z}_{0 \mathrm{~m}}$ values for all surface types were not a single value but showed some scatters as pointed out in the previous study (Yang et al. 2008).

\subsection{Roughness Length for Water Vapor}

The roughness length for water vapor $\mathrm{z}_{0 \mathrm{q}}$ was calculated from the integrated flux-gradient relationship as

$Q-Q_{s f c}=\frac{q^{*}}{k}\left[\ln \left(\frac{z-d}{z_{0 q}}\right)-\psi_{q}\left(\frac{z-d}{L}\right)+\psi_{q}\left(\frac{z_{0 q}}{L}\right)\right]$

where $Q$ is the specific humidity at $2 \mathrm{~m}$ height; $Q_{s f c}$, the spe- cific humidity at the surface; $q_{*}$, the scaling parameter for water vapor flux; and $\psi_{q}$, the stability correction. Though there is a study arguing different stability functions for water vapor and heat (Park et al. 2009), due to its minor effect and for simplicity, $\psi_{T}$ functions based on Dyer (1974) were used. For the snow surface, $Q_{s f c}$ was assumed to be saturated value at $T_{s f c}$. For the bare soil, $Q_{s f c}$ was calculated as the saturated humidity at the surface temperature $Q_{s a t}\left(T_{s f c}\right)$ times relative humidity at the surface $R H_{\text {sfc. }}$. The $R H_{s f c}$ was calculated following the approach of Noilhan and Planton (1989) with soil parameters of loam (Garratt 1992). For the senescent grass surface, relative humidity at the grass surface was not available, so that the $\mathrm{z}_{0 \mathrm{q}}$ defined using $T_{s f c}$ should be interpreted as the "apparent $\mathrm{z}_{0 \mathrm{q}}$ " (Kotani and Sugita 2005).

The surface temperature $T_{s f c}$ in the FLOSS-II data was calculated from the longwave radiation measurement corrected for the reflected downward longwave radiation as

$T_{s f c}=\left\{\left[R_{l u}-(1-\varepsilon) R_{l d}\right] / \varepsilon \sigma\right\}^{1 / 4}$

where $R_{l u}$ and $R_{l d}$ are upward and downward longwave radiations, respectively; $\varepsilon$ is longwave emissivity of the surface, and $\sigma$ is the Stephen-Boltzman constant (Kotani and Sugita $2005)$. In this study, the emissivity $(\varepsilon)$ of $0.96,0.95$, and 0.96 was used for bare soil, snow, and grass, respectively (Garratt 1992).

\section{RESULTS}

The magnitude and diurnal variation of the estimated $\mathrm{z}_{0 \mathrm{q}}$ and the parameter $\mathrm{kB}_{\mathrm{q}}{ }^{-1}=\ln \left(\mathrm{z}_{0 \mathrm{~m}} / \mathrm{z}_{0 \mathrm{q}}\right)$ for each surface type were examined. An optimal regression function for $\mathrm{kB}_{\mathrm{q}}^{-1}$ as a function of $\mathrm{Re}_{*}$ was deduced for each surface type. Once $\mathrm{kB}_{\mathrm{q}}^{-1}$ is determined, $\mathrm{z}_{0 \mathrm{q}}$ can be obtained as $\mathrm{z}_{0 \mathrm{q}}=$ $\mathrm{z}_{0 \mathrm{~m}} \exp \left(-\mathrm{kB}_{\mathrm{q}}{ }^{-1}\right)$. Optimally regressed functions for $\mathrm{kB}_{\mathrm{q}}{ }^{-1}$ were
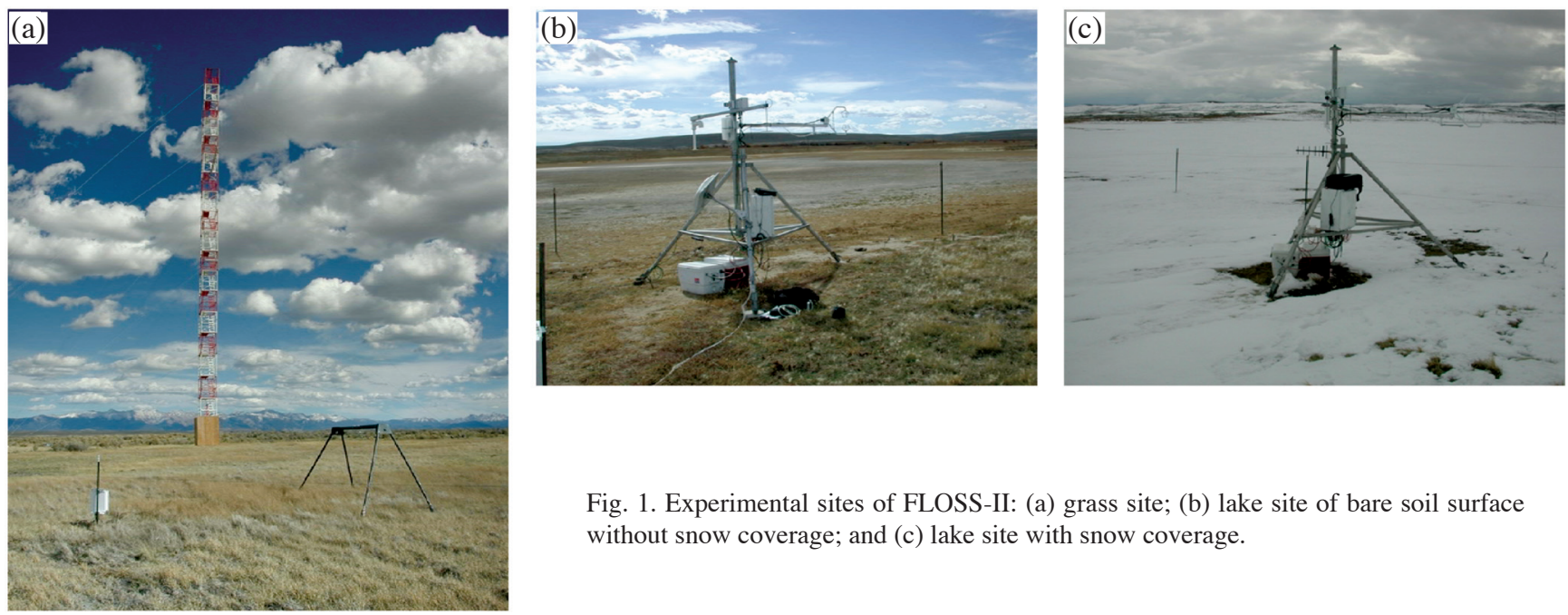

Fig. 1. Experimental sites of FLOSS-II: (a) grass site; (b) lake site of bare soil surface without snow coverage; and (c) lake site with snow coverage. 
Meteorological Conditions during FLOSS-II Experiment

(a)

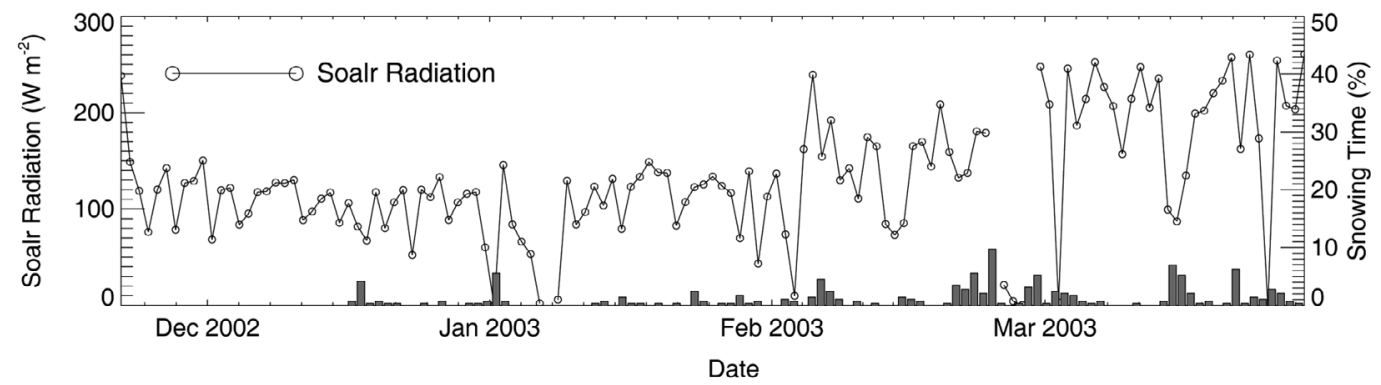

(b)

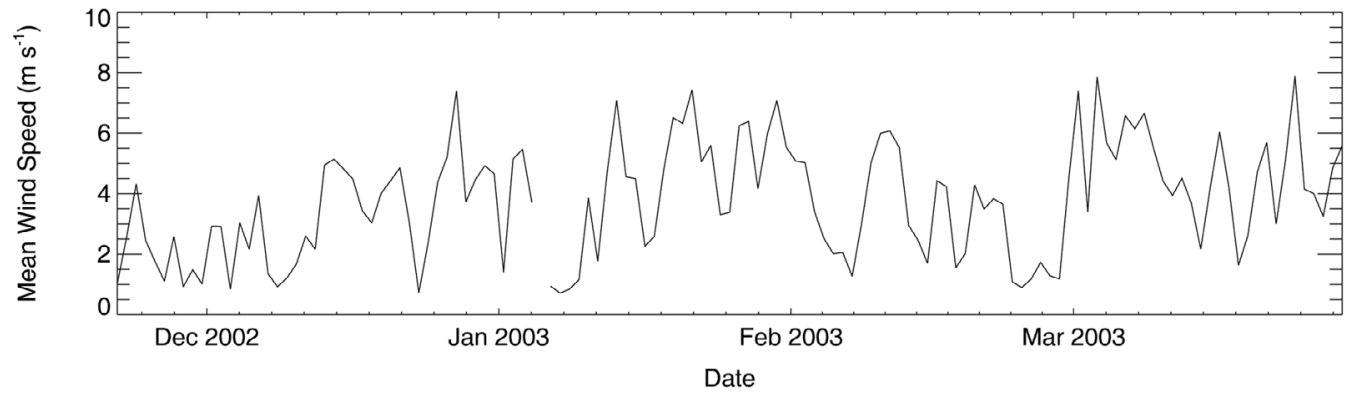

(c)

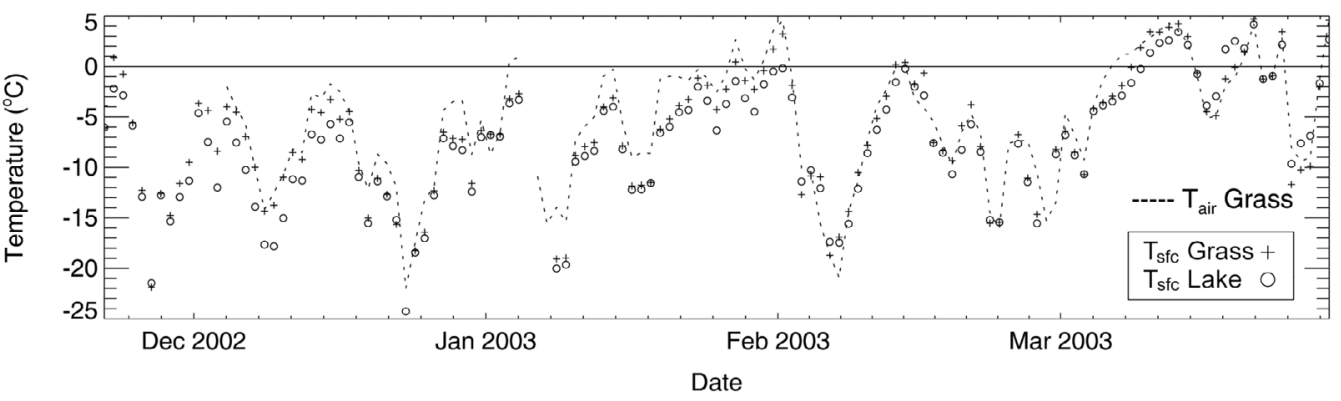

(d)

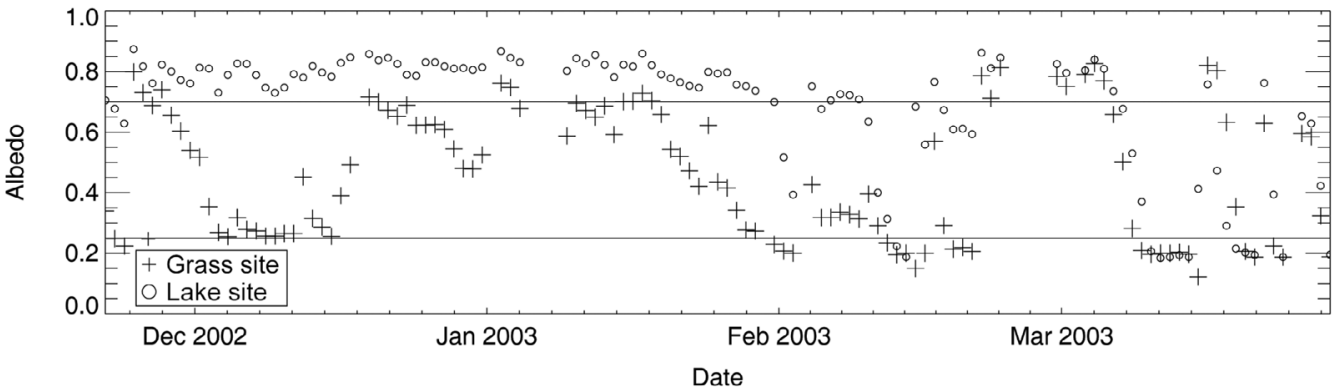

(e)

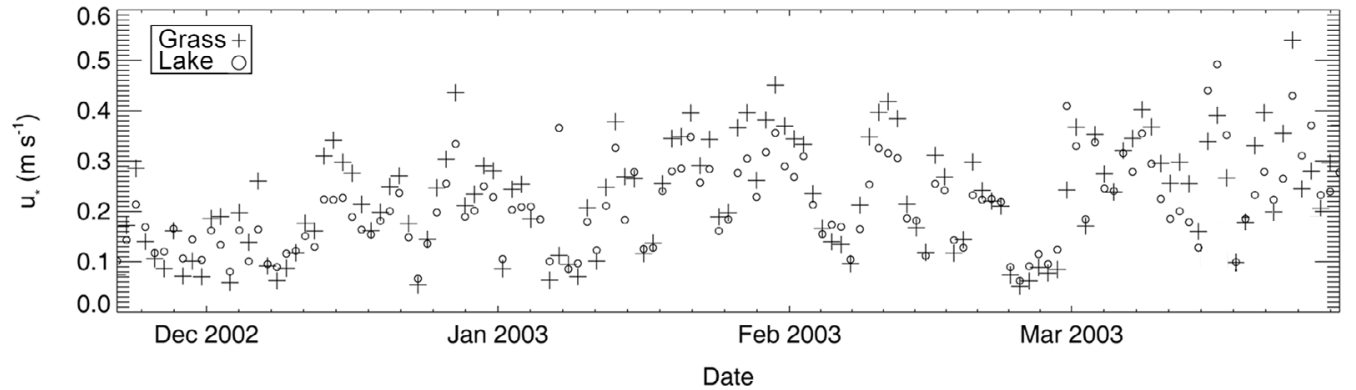

Fig. 2. Meteorological conditions during the FLOSS-II experimental period: (a) daily mean solar radiation (circle, $\mathrm{W} \mathrm{m}^{-2}$ ) and the fraction of snowfall time for a day (bar, \%); (b) daily mean wind speed $\left(\mathrm{m} \mathrm{s}^{-1}\right)$; (c) daily mean air temperature (dotted line, $\left.{ }^{\circ} \mathrm{C}\right)$ at the grass site, and daily mean surface temperatures $\left({ }^{\circ} \mathrm{C}\right)$ at the grass site $(+)$ and the lake site $(\mathrm{O}) ;(\mathrm{d})$ daily mean albedo at the grass site $(+)$ and the lake site $(\mathrm{O})$. Note that precipitation data are missing until December 17; (e) daily mean friction velocity $\left(\mathrm{m} \mathrm{s}^{-1}\right)$; (f) daily mean humidity scale $\left(\mathrm{g} \mathrm{kg}^{-1}\right)$; (g) daily mean Re* and (h) daily mean stability $\mathrm{z} / \mathrm{L}$ at the grass site (+) and the lake site (O). 
(f)

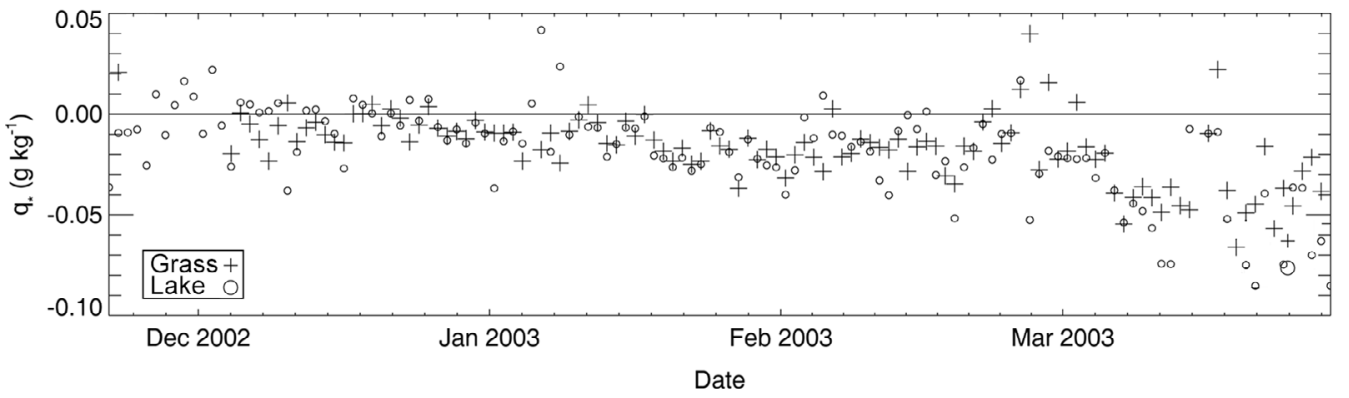

(g)

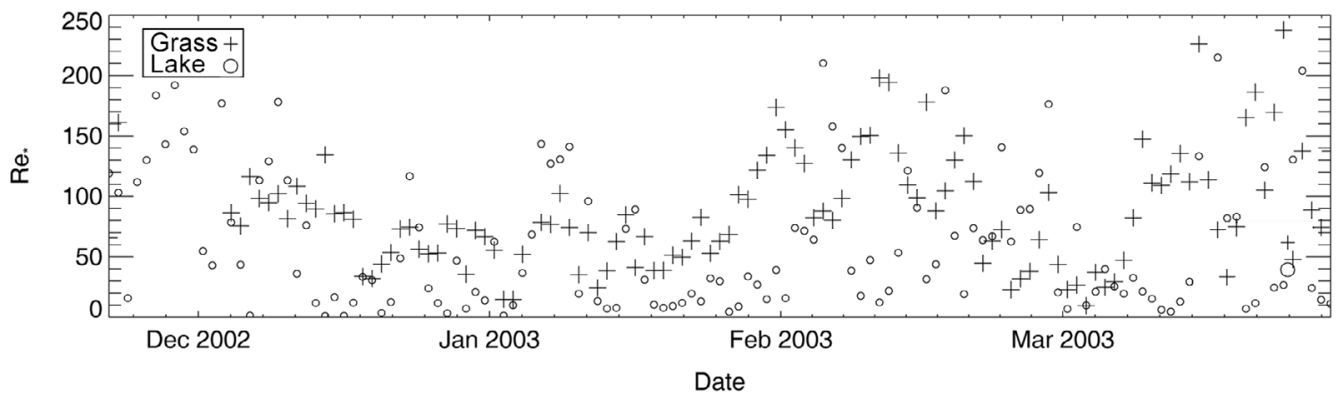

(h)

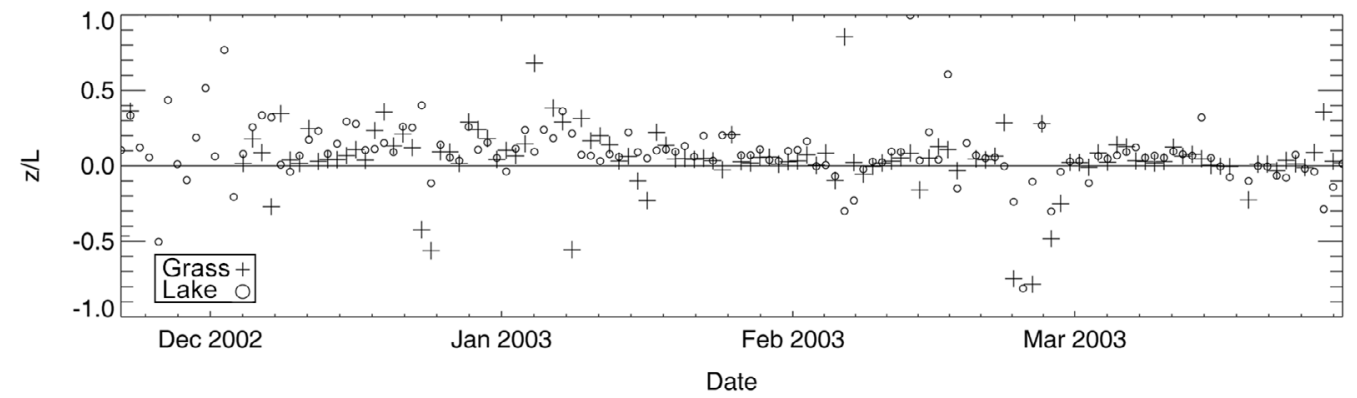

Fig. 2. (continued)

(a)

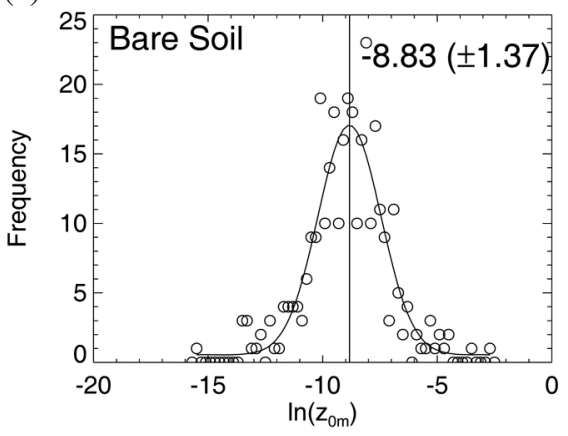

(b)

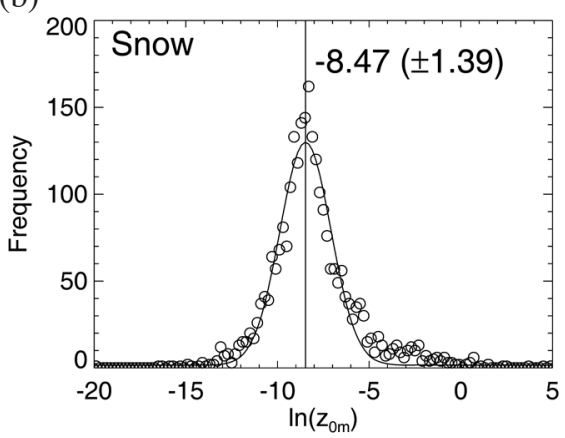

(c)

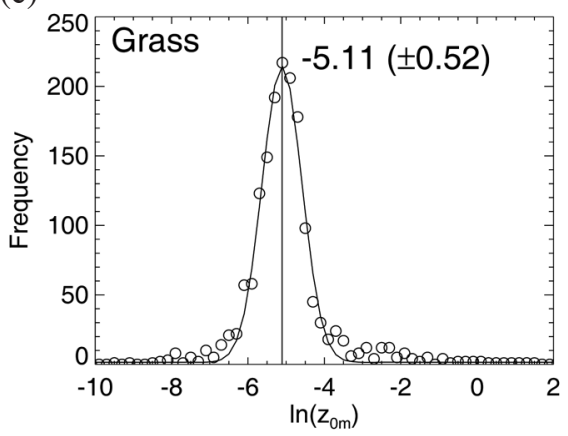

Fig. 3. Distribution of momentum roughness length $z_{0 m}$ for (a) the bare soil, (b) the snow, and (c) the senescent grass surfaces.

compared with the reference functions based on errors in the latent heat flux.

\subsection{Roughness Length for Water Vapor and $\mathrm{kB}_{\mathrm{q}}{ }^{-1}$}

Estimated $\mathrm{z}_{0 \mathrm{q}}$ and $\mathrm{kB}_{\mathrm{q}}^{-1}$ for each surface are presented in Fig. 4: Figs. $4 \mathrm{~d}$ and $\mathrm{g}$ for the bare soil; Figs. $4 \mathrm{e}$ and $\mathrm{h}$ for the snow; Figs. 4f and i for the grass. Momentum roughness $\mathrm{z}_{0 \mathrm{~m}}$ and $\mathrm{Re}_{*}$ are also shown for the bare soil (Figs. $4 \mathrm{a}$ and $\mathrm{j}$ ), snow (Figs. $4 \mathrm{~b}$ and $\mathrm{k}$ ), and grass (Figs. $4 \mathrm{c}$ and $\mathrm{l}$ ). The $\mathrm{z}_{0 \mathrm{q}}$ $\left(\mathrm{kB}_{\mathrm{q}}{ }^{-1}\right)$ showed a distinct diurnal variation with a minimum (maximum) during the daytime and a maximum (minimum) during the nighttime at all surface types, with the largest variation occurring over the senescent grass surface. 

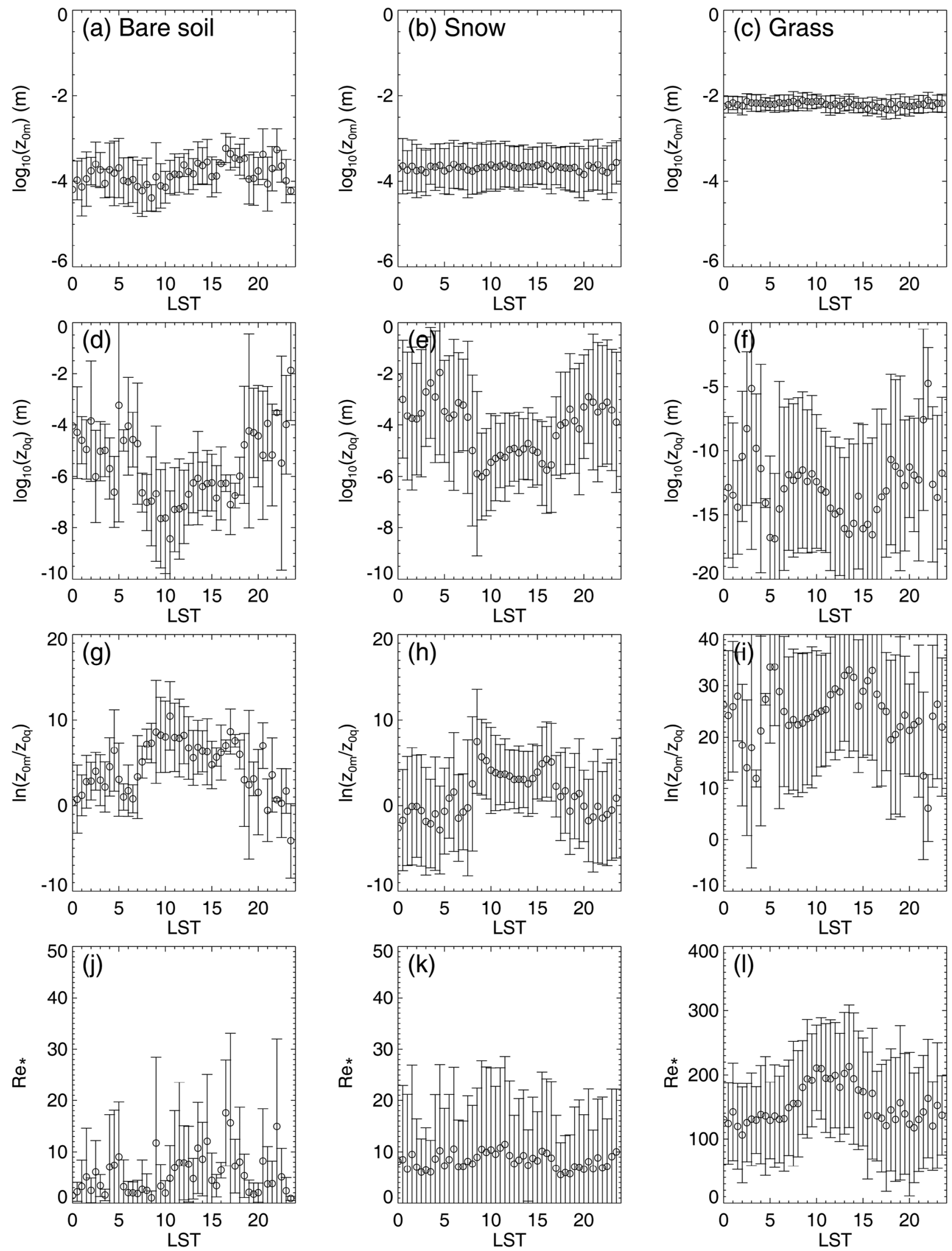

Fig. 4. Diurnal variation of the observed $\mathrm{z}_{0 \mathrm{~m}}\left(1^{\text {st }}\right.$ row $), \mathrm{z}_{0 \mathrm{q}}\left(2^{\text {nd }}\right.$ row $), \mathrm{kB}_{\mathrm{q}}{ }^{-1}\left(3^{\text {rd }}\right.$ row $)$, and $\mathrm{Re}_{*}\left(4^{\text {th }}\right.$ row $)$ for the bare soil surface $\left(1^{\text {st }}\right.$ column $)$, the snow surface $\left(2^{\text {nd }}\right.$ column $)$, and the grass surface $\left(3^{\text {rd }}\right.$ column $)$. Circles $(O)$ denote mean values and the error-bars denote one standard deviation. 
Although $\mathrm{z}_{0 \mathrm{~m}}$ remained approximately $10^{-4} \mathrm{~m}$ for bare soil, $10^{-4} \mathrm{~m}$ for snow, and $10^{-2} \mathrm{~m}$ for grass surfaces without diurnal variation, $\mathrm{z}_{0 \mathrm{q}}$ changed from minima of about $10^{-7}, 10^{-6}$, and $10^{-15} \mathrm{~m}$ during the daytime to maxima of about $10^{-4}, 10^{-3}$, and $10^{-10} \mathrm{~m}$ during the nighttime for the bare soil, snow, and grass surfaces, respectively. Consequently, $\mathrm{kB}_{\mathrm{q}}^{-1}$ reached about 10,8 , and 30 during the daytime and decreased to 0 , -3 , and 10 during the nighttime for the bare soil, snow, and grass surfaces, respectively. The negative $\mathrm{kB}_{\mathrm{q}}{ }^{-1}$ values, implying $\mathrm{z}_{0 \mathrm{q}}>\mathrm{z}_{0 \mathrm{~m}}$, also occurred frequently during the nighttime at the bare soil and snow surfaces.

The variations of $\mathrm{kB}_{\mathrm{q}}^{-1}$ with $\operatorname{Re}_{*}\left(=\mathrm{z}_{0 \mathrm{~m}} \mathrm{u}_{*} v^{-1}\right.$, where $\mathrm{u}_{*}$ is the friction velocity and $v$ is the kinematic viscosity of air) are shown for the bare soil (Fig. 5a), snow (Fig. 5b), and grass (Fig. 5c) surfaces, respectively, with the selected reference functions for $\mathrm{kB}_{\mathrm{q}}^{-1}$ listed in Table 1. Distributions of occurrence frequency of $\mathrm{kB}_{\mathrm{q}}^{-1}$ with $\mathrm{Re}_{*}$ are also presented. Most of the data distributed in the range of $10^{-0.5}<\mathrm{Re}_{*}<$ $10^{1.5}$ (Fig. 5d), $10^{-0.5}<\operatorname{Re}_{*}<10^{1.5}$ (Fig. 5e), $10^{1.5}<\operatorname{Re}_{*}<$ $10^{2.5}$ (Fig. 5f) for the bare soil, snow, and grass surfaces, respectively. As previously shown, $\mathrm{kB}_{\mathrm{q}}{ }^{-1}$ increased as $\mathrm{Re} *$ increased (air flow gets rougher), and negative $\mathrm{kB}_{\mathrm{q}}^{-1}$ occurred in the smooth flow regime of small $\mathrm{Re}_{*}$ values. However, the presently observed $\mathrm{kB}_{\mathrm{q}}^{-1}$ was larger than the previous estimation by about 3 to 5 at the bare soil surface and the grass surface, whereas $\mathrm{kB}_{\mathrm{q}}{ }^{-1}$ was smaller than the estimation
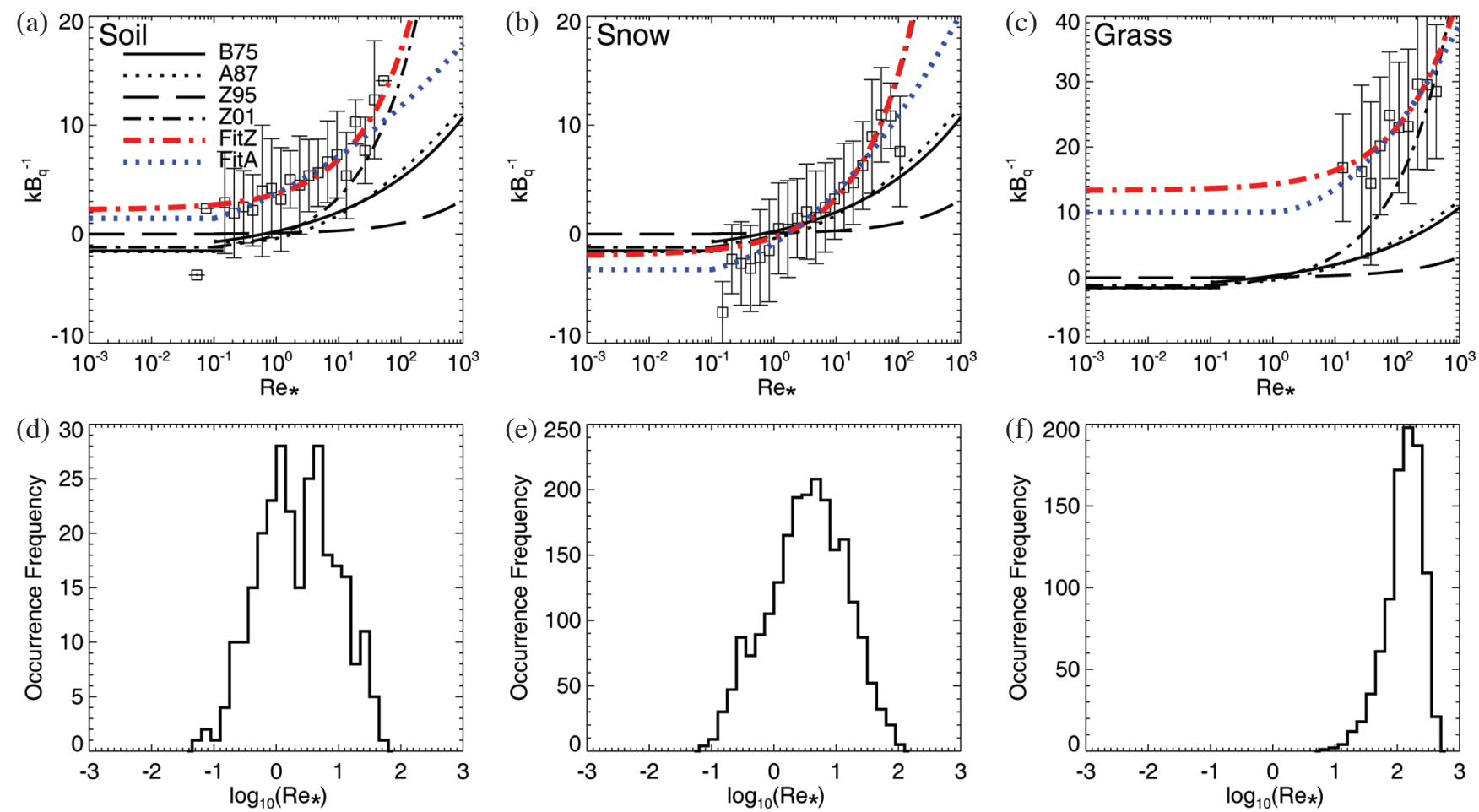

Fig. 5. Optimally regressed functions for $\mathrm{kB}_{\mathrm{q}}{ }^{-1} \mathrm{FitZ}$ (red line) and FitA (blue line) for (a) the bare soil, (b) the snow, and (c) the grass surfaces. Reference functions are listed in Table 1. Occurrence frequency of the observed data in each $\operatorname{Re}_{*}$ bin is shown below each surface type. Marks ( $\square$ ) denote mean values and the error-bars denote one standard deviations for each $\operatorname{Re}_{*}$ bin.

Table 1. Selected parameterizations for $\mathrm{kB}_{\mathrm{q}}^{-1}\left[=\ln \left(\mathrm{z}_{\mathrm{om}} / \mathrm{z}_{\mathrm{qq}}\right)\right]$. Note that Andreas (1987) had a separate formula for the transition regime $(0.135<$ $\operatorname{Re}_{*}<2.5$, not shown in this table).

\begin{tabular}{llll}
\hline Author & Smooth flow $\left(\mathbf{R e}_{*}<\mathbf{0 . 1 3 5}\right)$ & Rough flow $\left(\mathbf{R e}_{*}>\mathbf{0 . 1 3 5}\right)$ & Comment \\
\hline Brutsaert (1975) & $\mathrm{k}\left(13.6 \mathrm{Sc}^{2 / 3}-13.5\right)$ & $7.3 \operatorname{Re}_{*}^{0.25} \mathrm{Sc}^{0.5}-5$ & Bluff-rough surface \\
Andreas (1987) & -1.61 & $-0.396+0.512 \ln \left(\operatorname{Re}_{*}\right)+0.180 \ln ^{2}\left(\operatorname{Re}_{*}\right)$ for $\left(\operatorname{Re}_{*}>2.5\right)$ & Snow/ice \\
Zilitinkevich (1995) & $0.1 \operatorname{Re}_{*}^{0.5}$ & $0.1 \operatorname{Re}_{*}^{0.5}$ & Sea \\
Zilitinkevich et al. (2001) & $-3 \mathrm{k}$ & $1.6 \operatorname{Re}_{*}^{0.5}-1.68$ & \\
\hline
\end{tabular}


in the smooth flow regime of the snow surface. Among the reference functions, $\mathrm{kB}_{\mathrm{q}}^{-1}$ of Zilitinkevich et al. (2001) obtained over water surface showed the best agreement with the observed $\mathrm{kB}_{\mathrm{q}}{ }^{-1}$ of the snow surface. This implies that smooth and saturated snow surface behaves similarly to the water surface of Zilitinkevich et al. (2001).

\subsection{Parameterization for $\mathrm{kB}_{\mathrm{q}}{ }^{-1}$}

Because $\mathrm{Re}_{*}$ indicated high correlation with the observed $\mathrm{kB}_{\mathrm{q}}^{-1}$, an optimal fitting of $\mathrm{kB}_{\mathrm{q}}{ }^{-1}$ with $\mathrm{Re}_{*}$ was conducted. Among others, two types of regression functions were selected: a linear function of $\mathrm{Re}_{*}$ with some exponents as in Zilitinkevich et al. (2001) and a rather unique form of quadratic function of $\ln \left(\mathrm{Re}_{*}\right)$ as in Andreas (1987). Hereafter, we denote the former as "FitZ," the latter as "FitA" and the reference functions are denoted as "Z01" and "A87," respectively. For the FitZ fitting, the exponent of $\mathrm{Re}_{*}$ was fixed to 0.5 because it performed equally well showing the same magnitude of error compared to different exponents of 0.25 or 0.45 in some earlier studies (Brutsaert 1975; Zeng and Dickinson 1998).

The optimally regressed functions obtained in this study are listed in Table 2 and the profiles are shown in Fig. 5. It is noted that FitZ for the snow surface is quite similar to Z01. This similarity is reliable because snow surface resembles the water surface considering their characteristics in a smooth and saturated surface. The parameterized $\mathrm{kB}_{\mathrm{q}}{ }^{-1}$ values from fitted function are compared to the observed
$\mathrm{kB}_{\mathrm{q}}^{-1}$ in Fig. 6, with correlation coefficient and mean bias for each surface type: Figs. $6 a, d, g, j$, and $m$ for the bare soil; Figs. 6b, e, h, k, and n for the snow; Figs. 6c, f, i, 1, and o for the grass. Optimally regressed functions FitZ (Figs. 6g, h, and i) and FitA (Figs. 6j, k, and l) showed slight improvement in correlation but greatly reduced biases compared to the reference functions (Figs. 6a - f) for all surface types.

For further improvement of correlation coefficients, the difference (i.e., the residual $\mathrm{kB}_{\mathrm{q}}{ }^{-1}$ ) between the regressed $\mathrm{kB}_{\mathrm{q}}^{-1}$ and the observed $\mathrm{kB}_{\mathrm{q}}^{-1}$ was examined in relation with other variables. It is found that relative humidity $(\mathrm{RH})$ measured at $2 \mathrm{~m}$ height showed a moderate relation $(\mathrm{R} \sim 0.4$, not shown) with the residual $\mathrm{kB}_{\mathrm{q}}{ }^{-1}$. Because FitZ and FitA showed similar agreement with the observed $\mathrm{kB}_{\mathrm{q}}{ }^{-1}$, only FitZ was used to demonstrate the improvement by additional term of RH. A simple linear term of RH was added to FitZ and this new function is denoted as "FitZC" which means a FitZ combined with RH fitting. FitZC functions for the three surface types are also listed in Table 2 with FitZ and FitA. FitZC showed higher correlation than FitZ and Z01 functions (Figs. 6m, n, and o). This might be attributed to the diurnal variation of $\mathrm{RH}$ enabling FitZC to have more distinct diurnal variation as the observed $\mathrm{kB}_{\mathrm{q}}^{-1}$.

\subsection{Evaluation of Flux Estimation}

To evaluate the present optimal functions, errors were compared using various $\mathrm{kB}_{\mathrm{q}}^{-1}$ functions in terms of the exchange coefficient $\mathrm{Ce}$ and the latent heat flux, which were

Table 2. Optimally fitted functions for $\mathrm{kB}_{\mathrm{q}}{ }^{-1}$. Functions using the form of Zilitinkevich (2001) and Andreas (1987) are named as FitZ and FitA, respectively. FitZC denotes FitZ with additional linear function of $\mathrm{RH}(\%)$.

\begin{tabular}{|c|c|c|c|}
\hline Function Type & Surface Type & Smooth flow & Rough flow \\
\hline \multirow[t]{3}{*}{ FitZ } & Soil & 2.17 & $2.24 \operatorname{Re}_{*}^{0.5}+1.46$ \\
\hline & Snow & -1.43 & $1.68 \operatorname{Re}_{*}^{0.5}-1.96$ \\
\hline & Grass & 13.67 & $0.97 \operatorname{Re}_{*}^{0.5}+13.36$ \\
\hline \multirow[t]{4}{*}{ FitA } & Soil & 1.444 & $\mathrm{~b}_{0}+\mathrm{b}_{1} \ln \left(\mathrm{Re}_{*}\right)+\mathrm{b}_{2} \ln \left(\mathrm{Re}_{*}\right)^{2}$ \\
\hline & & & $\mathrm{b}_{0} / \mathrm{b}_{1} / \mathrm{b}_{2}=3.712 / 1.237 / 0.109$ \\
\hline & Snow & -3.248 & $\mathrm{~b}_{0} / \mathrm{b}_{1} / \mathrm{b}_{2}=-0.844 / 1.545 / 0.218$ \\
\hline & Grass & 9.998 & $\mathrm{~b}_{0} / \mathrm{b}_{1} / \mathrm{b}_{2}=10.024 / 0.244 / 0.567$ \\
\hline \multirow[t]{4}{*}{ FitZC } & Soil & \multicolumn{2}{|c|}{ FitZC = FitZ + g(RH) } \\
\hline & & \multicolumn{2}{|c|}{$\mathrm{g}(\mathrm{RH})=5.016-0.090 \mathrm{RH}, \mathrm{RH}$ in $\%$} \\
\hline & Snow & \multicolumn{2}{|c|}{$\mathrm{g}(\mathrm{RH})=5.990-0.084 \mathrm{RH}$} \\
\hline & Grass & \multicolumn{2}{|c|}{$g(R H)=21.152-0.391 R H$} \\
\hline
\end{tabular}


(a) Soil

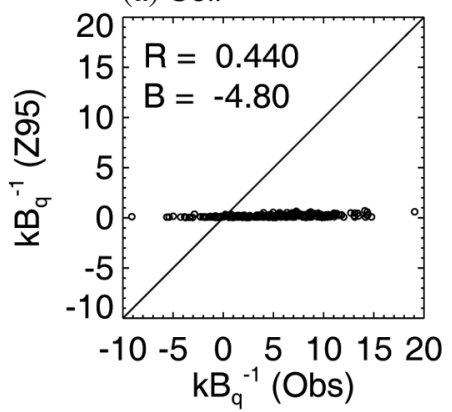

(d) Soil

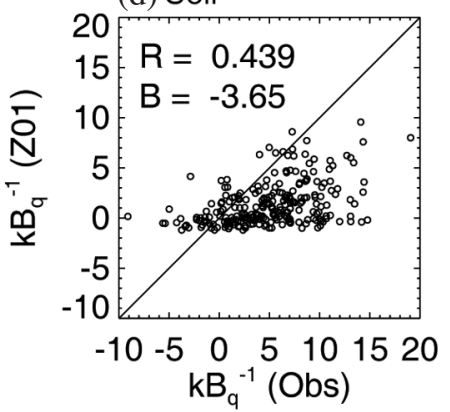

(g) Soil
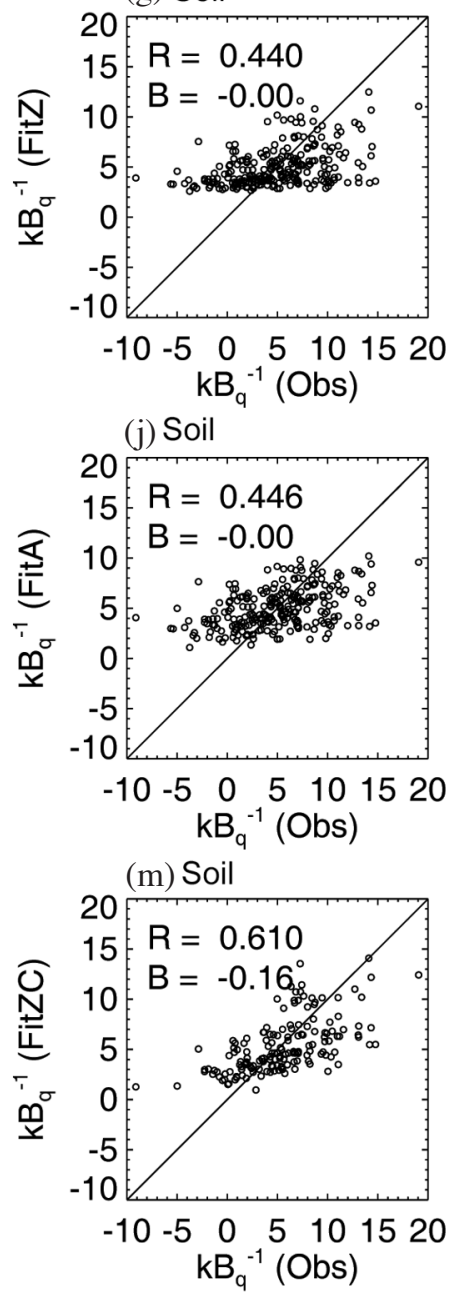

(b) Snow

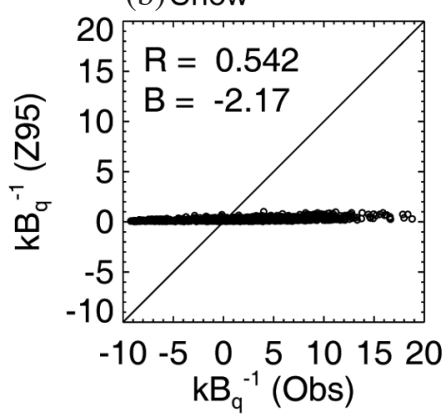

(e) Snow

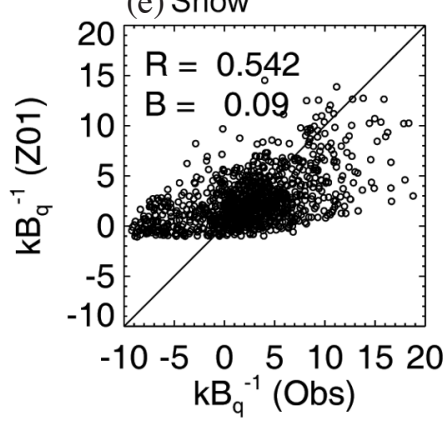

(h) Snow
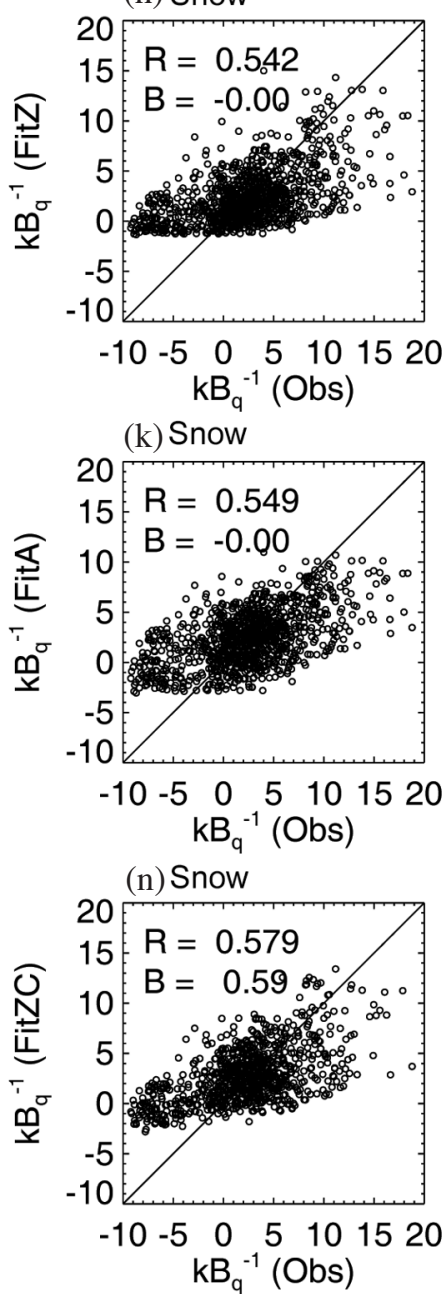

(c) Grass

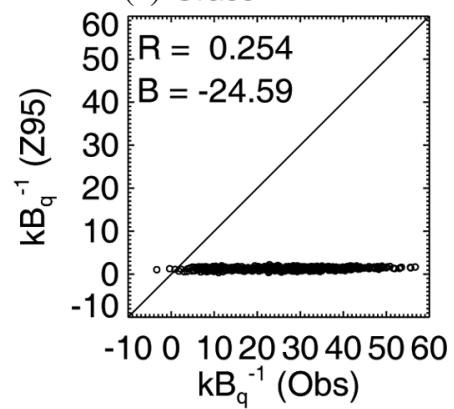

(f) Grass

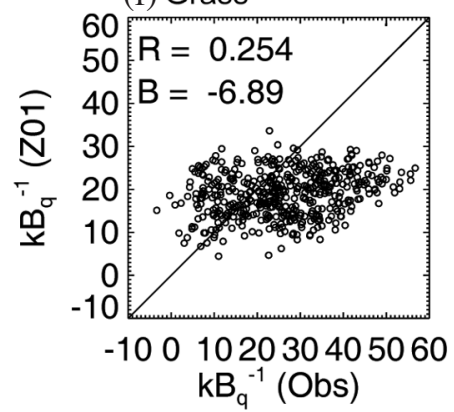

(i) Grass

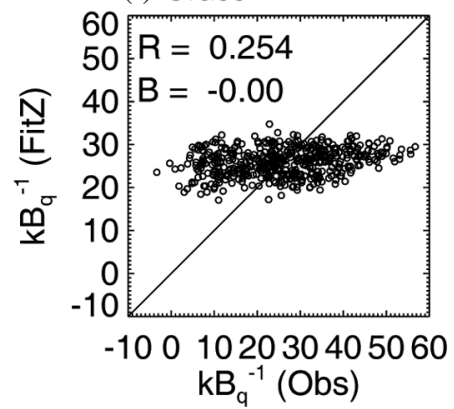

(1) Grass

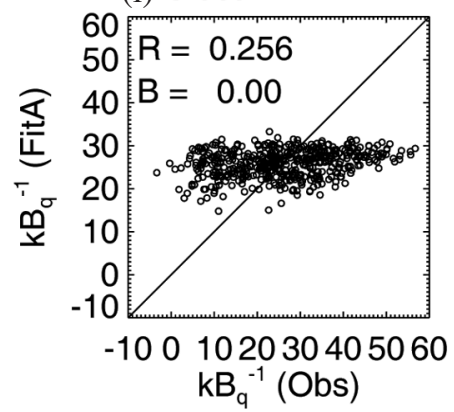

(o) Grass

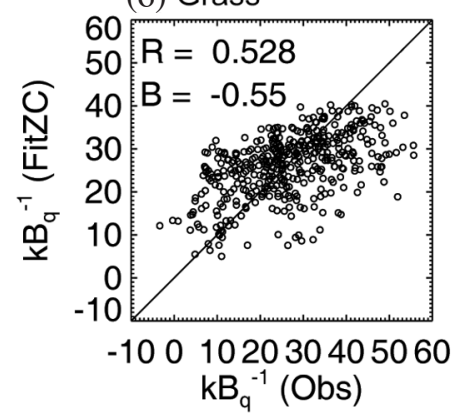

Fig. 6. Comparison of the parameterized $\mathrm{kB}_{\mathrm{q}}^{-1}$ (ordinate) with the observed $\mathrm{kB}_{\mathrm{q}}^{-1}$ (abscissa) for (left column) the soil surface, (middle column) the snow surface, and (right column) the grass surface. Functions are of Z95, Z01, FitZ, FitA, and FitZC from top to bottom. Correlation coefficient (R) and mean bias (B) are shown for each comparison. 
defined as differences in the following:

$$
\begin{aligned}
& C e_{o b s}=\frac{k^{2}}{\left[\ln \left(\frac{z-d}{z_{0 m}}\right)-\psi_{m}\left(\frac{z-d}{L}\right)\right]\left[\ln \left(\frac{z-d}{z_{0_{o b s}}}\right)-\psi_{q}\left(\frac{z-d}{L}\right)\right]} \\
& C e_{f t n}=\frac{k^{2}}{\left[\ln \left(\frac{z-d}{z_{0 m}}\right)-\psi_{m}\left(\frac{z-d}{L}\right)\right]\left[\ln \left(\frac{z-d}{z_{0 q_{f f n}}}\right)-\psi_{q}\left(\frac{z-d}{L}\right)\right]}
\end{aligned}
$$

$L H F_{o b s}=\rho L_{\nu} \overline{w^{\prime} q^{\prime}}$

and

$L H F_{f t n}=\rho L_{\nu} C e_{f t n} U\left(Q_{s f c}-Q\right)$

where $z_{0 q_{0 b s}}$ is the $z_{0 q}$ estimated from the observed latent heat flux [Eq. (2)], $z_{0 q_{f n}}$ estimated using $\mathrm{kB}_{\mathrm{q}}^{-1}$ parameterization, $\rho$ the air density, $L_{\nu}$ the latent heat for vaporization.

The resulting error statistics for the bare soil surface are shown in Fig. 7 as an example. Presently obtained functions (Figs. 7e and $\mathrm{g}$ ) reduced the overestimated $\mathrm{Ce}$ value of Z01 (Fig. 7c), thereby reducing errors in latent heat flux calculations (Figs. $7 \mathrm{f}$ and $\mathrm{h}$ ). Among reference functions, Z01 (Figs. 7c and d) showed quite reasonable results for the current observations (Z95 function is shown for comparison). Other reference functions tended to overestimate $\mathrm{Ce}$ due to underestimation of $\mathrm{kB}_{\mathrm{q}}^{-1}$ (or overestimation of $\mathrm{z}_{0 \mathrm{q}}$ ), thereby causing overestimation of the latent heat flux. $\mathrm{Ce}$ calculated using $\mathrm{z}_{0 \mathrm{q}}$ from Zilitinkevich (1995) overestimated latent heat flux of about $50 \%, 25 \%$, and $360 \%$ for the bare soil, snow, and grass surfaces, respectively (Figs. 7a and b; results for the snow and the grass surfaces are not shown).

\section{SUMMARY AND DISCUSSION}

The moisture roughness length $\mathrm{z}_{0 \mathrm{q}}$ was estimated using a four-month period of FLOSS-II experiment data obtained over high altitude flat regions for the three surface types: bare soil, snow, and senescent grass. The estimated $z_{0 q}$ and $\mathrm{kB}_{\mathrm{q}}^{-1}$ showed distinct diurnal variations as observed in $\mathrm{z}_{\mathrm{OT}}$ and $\mathrm{kB}_{\mathrm{T}}{ }^{-1}$ (Verhoef et al. 1997; Sun 1999; Yang et al. 2008). Magnitudes of the estimated $\mathrm{z}_{0 \mathrm{q}}$ were on the order of $10^{-7}$ to $10^{-4}, 10^{-6}$ to $10^{-3}$, and $10^{-15}$ to $10^{-10} \mathrm{~m}$ for the bare soil, snow, and grass surfaces, respectively. The corresponding $\mathrm{kB}_{\mathrm{q}}^{-1}$ were about 0 to $10,-3$ to 8 , and 10 to 30 for the bare soil, snow, and grass surfaces, respectively. The increase of $\mathrm{kB}_{\mathrm{q}}{ }^{-1}$ with the increase of $\mathrm{Re}_{*}$ was confirmed in the rough flow regime, and negative $\mathrm{kB}_{\mathrm{q}}{ }^{-1}$ values $\left(\mathrm{z}_{0 \mathrm{q}}\right.$ larger than $\left.\mathrm{z}_{0 \mathrm{~m}}\right)$ were also observed in the smooth flow regime.

The present results show that $\mathrm{kB}_{\mathrm{q}}^{-1}$ is significantly larger than the previous estimations. This implies that $\mathrm{z}_{0 \mathrm{q}}$ is much smaller than previously estimated values over the bare soil and the grass surfaces. For the snow surface, the observed $\mathrm{kB}_{\mathrm{q}}{ }^{-1}$ agrees quite well with that of Zilitinkevich et al. (2001) in the rough flow regime $\left(\operatorname{Re}_{*}>1\right)$ within their limited value of $\operatorname{Re}_{*}<10$, whereas it is less than that of Zilitinkevich et al. (2001) by about 3 to 5 in the smooth flow regime $\left(\operatorname{Re}_{*}<1\right)$. It is found that previous parameterizations generally overestimate the exchange coefficient $\mathrm{Ce}$, consequently overestimate the latent heat flux over the bare soil and grass surfaces.

The variation of the observed $\mathrm{z}_{0 \mathrm{q}}$ with $\mathrm{Re}_{*}$ is consistent with previous studies in that $\mathrm{z}_{0 \mathrm{q}}$ values are typically much smaller than $\mathrm{z}_{0 \mathrm{~m}}$ in the rough flow regime while larger than $\mathrm{z}_{0 \mathrm{~m}}$ in the smooth flow regime (Brutsaert 1982; Zilitinkevich et al. 2001; Andreas 2002). The diurnal variation of $z_{0 q}$ is similar to the observed variation of $\mathrm{z}_{0 \mathrm{~T}}$ in previous studies (Verhoef et al. 1997; Yang et al. 2008). However, the present $z_{0 q}$ is much smaller than that of previous estimate over the bare soil and the grass surfaces, while it is larger than previous estimation in the smooth flow regime $\left(\operatorname{Re}_{*}<1\right)$ over the snow surface. Even though general explanation of the causes of the diurnal variation of $\mathrm{z}_{0 \mathrm{q}}$ is not yet suggested, the molecular diffusion in the interfacial layer might be a possible reason for the variation. During the daytime the depth of the interfacial layer $\left(30 \mathrm{vu}_{*}^{-1}\right)$ decreases as the friction velocity $\mathrm{u}_{*}$ increases. A new function FitZC for the diurnal variation of $\mathrm{kB}_{\mathrm{q}}^{-1}$ with the use of $\mathrm{RH}$ showed much better correlation with the observed $\mathrm{kB}_{\mathrm{q}}{ }^{-1}$ than other functions (Fig. 6). However, the error reduction in $\mathrm{Ce}$ and latent heat flux was of no significance compared to those of FitZ. Also the physical relation between $\mathrm{RH}$ and $\mathrm{kB}_{\mathrm{q}}{ }^{-1}$ was not clear, suggesting that further studies are necessary to provide robust explanation for the diurnal variation of $\mathrm{kB}_{\mathrm{q}}^{-1}$.

It is worth noting the limitations of the present study. First, even though soil moisture content is expected to be relevant to $\mathrm{kB}_{\mathrm{q}}^{-1}$ over the bare soil surface (Kotani and Sugita 2005), we were unable to find a clear relationship between them due to a narrow range of variation of the soil moisture content for the available data period. Second, the flow regime over the snow surface was limited within the range of $\operatorname{Re}_{*}<10^{2}$. Other observation made on rougher snow/ice surface as in Smeets and Broeke (2008) will be required to validate the new parameterization beyond the flow regime of $\operatorname{Re}_{*}>10^{2}$. Third, the separation of the wet and the dry conditions in the senescent grass surface could not be done. This will further improve the parameterization.

Despite these limitations, the presently derived parameterization of $\mathrm{kB}_{\mathrm{q}}^{-1}$ with $\mathrm{Re}_{*}$ will provide more accurate estimations of the exchange coefficient and the latent heat flux so as to be potentially used for the modeling of water and energy circulation over such regions of bare soil surfaces in the semi-arid regions and the snow-covered regions at highaltitudes or the polar region. 
(a) $\mathrm{Ce} \mathrm{Z95}$

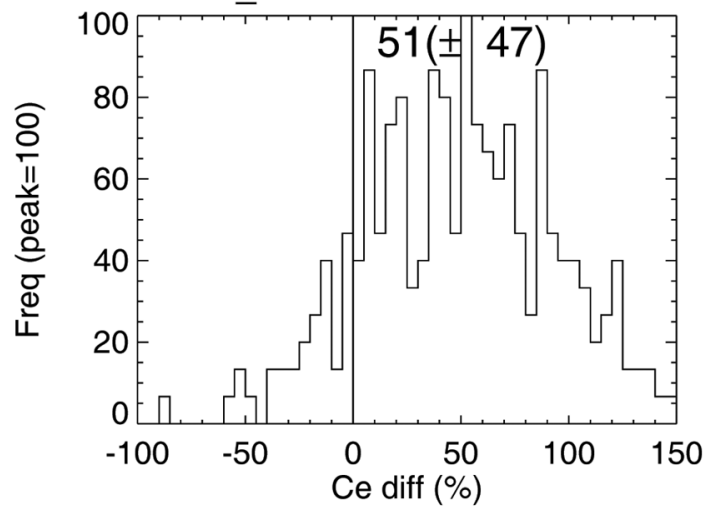

(c) Ce_Z01

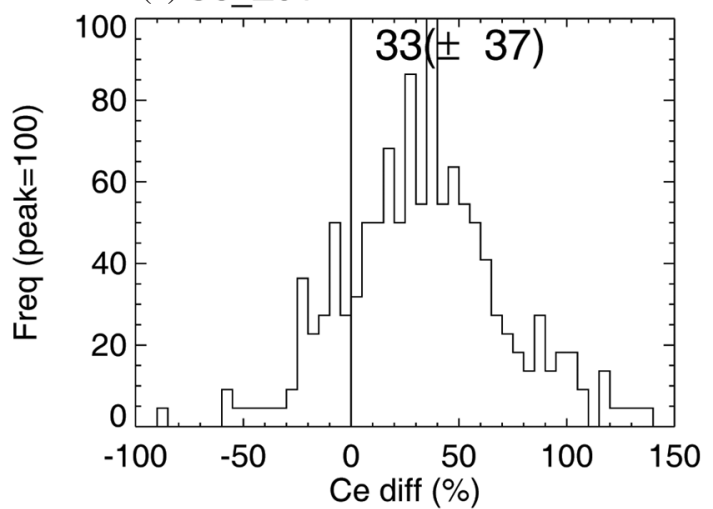

(e) Ce_FitZ

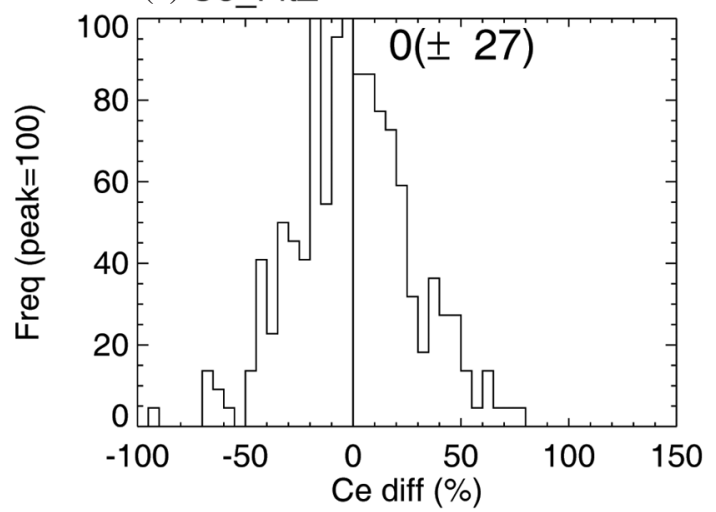

(g) Ce_FitZC

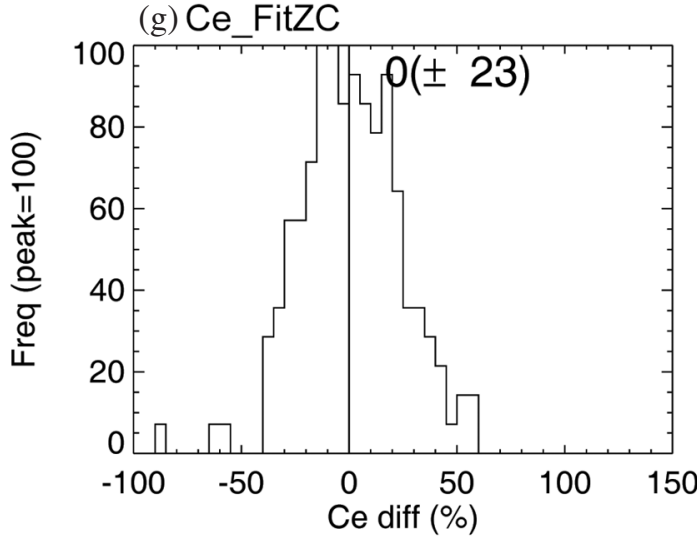

(b) LHF Z95

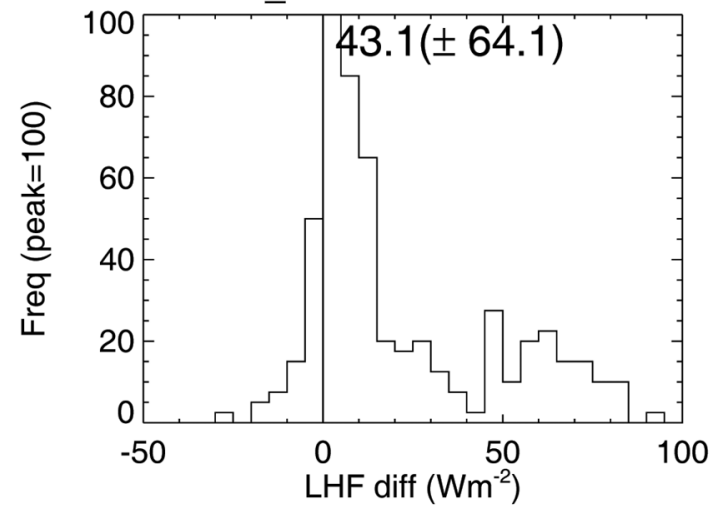

(d) LHF_Z01

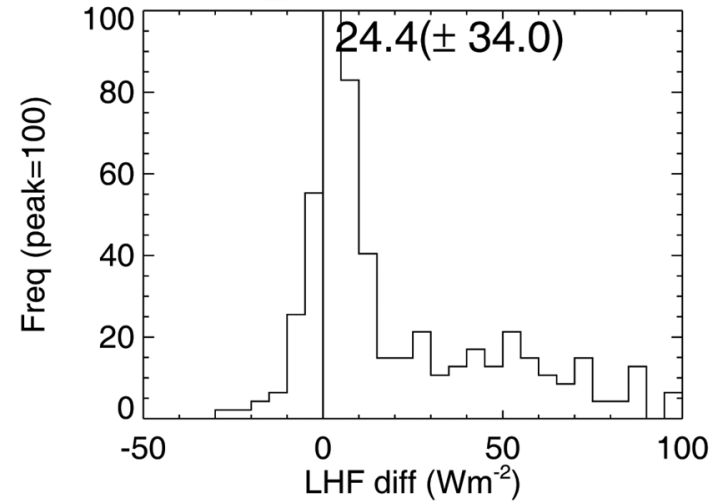

(f) LHF_FitZ

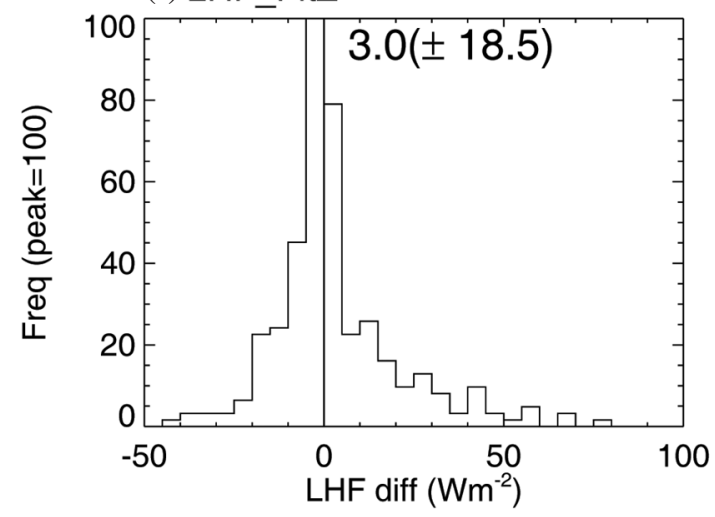

(h) LHF_FitZC

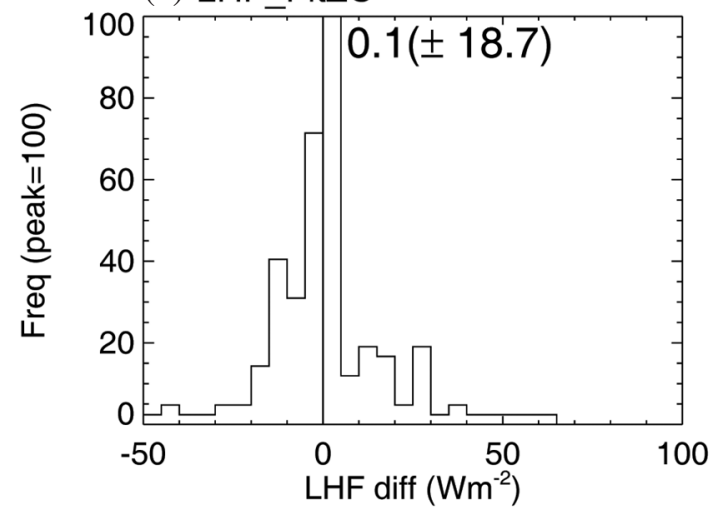

Fig. 7. Distributions of errors in the exchange coefficient $C e$ [Eq. (4)] and the latent heat flux [Eq. (5)] using functions of Z95, Z01, FitZ, and FitZC (from top to bottom): (left) distribution of $C e$ difference, and (right) distribution of the latent heat flux difference over the bare soil surface. Mean value and one standard deviation of error are shown for each case. 
Acknowledgements This study was supported by CATER 2006-4204. The authors would like to thank the National Center for Atmospheric Research (NCAR) Earth Observing laboratory (EOL) for their provision of the FLOSS-II dataset. The authors are grateful to Prof. C. H. Sui, Dr. A. Kotani, and two anonymous reviewers. Their helpful comments and suggestions led this study to a publishable work.

\section{REFERENCES}

Andreas, E. L., 1987: A theory for the scalar roughness and the scalar transfer coefficients over snow and sea ice. Bound.-Layer Meteor., 38, 159-184, doi: 10.1007/ BF00121562. [Link]

Andreas, E. L., 2002: Parameterizing scalar transfer over snow and ice: A review. J. Hydrometeorol., 3, 417432, doi: 10.1175/1525-7541(2002)003<0417:PSTOS $\mathrm{A}>2.0 . \mathrm{CO} ; 2$. [Link]

Bao, J. W., S. A. Michelson, and J. M. Wilczak, 2002: Sensitivity of numerical simulations to parameterizations of roughness for surface heat fluxes at high winds over the sea. Mon. Weather Rev., 130, 1926-1932, doi: 10. 1175/1520-0493(2002)130<1926:SONSTP>2.0.CO;2. [Link]

Beljaars, A. C. M. and A. A. M. Holtslag, 1991: Flux parameterization over land surfaces for atmospheric models. J. Appl. Meteorol., 30, 327-341, doi: 10.1175/1520-04 50(1991)030<0327:FPOLSF>2.0.CO;2. [Link]

Brutsaert, W., 1975: The roughness length for water vapor sensible heat, and other scalars. J. Atmos. Sci., 32, 2028-2031, doi: 10.1175/1520-0469(1975)032<2029: TRLFWV>2.0.CO;2. [Link]

Brutsaert, W., 1982: Evaporation into the Atmosphere: Theory, History, and Applications, Kluwer Academic Publishers, 299 pp.

Chen, F. and J. Dudhia, 2001: Coupling an advanced land surface-hydrology model with the Penn State-NCAR MM5 modeling system. Part I: Model implementation and sensitivity. Mon. Weather Rev., 129, 569-585, doi: 10.1175/1520-0493(2001)129<0569:CAALSH>2.0.C O;2. [Link]

Chen, F., Z. Janjic, and K. Mitchell, 1997: Impact of atmospheric surface-layer parameterizations in the new land-surface scheme of the NCEP mesoscale Eta model. Bound.-Layer Meteor., 85, 391-421, doi: 10.1023/ A:1000531001463. [Link]

Demuzere, M., K. De Ridder, and N. P. M. Van Lipzig, 2008: Modeling the energy balance in Marseille: Sensitivity to roughness length parameterizations and thermal admittance. J. Geophys. Res., 113, D16120, doi: 10.1029/2007JD009113. [Link]

Dyer, A. J., 1974: A review of flux-profile relationships. Bound.-Layer Meteor., 7, 363-372, doi: 10.1007/BF00 240838. [Link]
Edson, J. B., C. J. Zappa, J. A. Ware, W. R. McGillis, and J. E. Hare, 2004: Scalar flux profile relationships over the open ocean. J. Geophys. Res., 109, C08S09, doi: 10.1029/2003JC001960. [Link]

Fairall, C. W., E. F. Bradley, J. E. Hare, A. A. Grachev, and J. B. Edson, 2003: Bulk parameterization of air-sea fluxes: Updates and verification for the COARE algorithm. J. Climate, 16, 571-591, doi: 10.1175/1520-044 2(2003)016<0571:BPOASF>2.0.CO;2. [Link]

Garratt, J. R., 1992: The Atmospheric Boundary Layer, Cambridge Atmospheric and Space Science Series, Cambridge University Press, Cambridge, 316 pp.

Horst, T. W., 2003: Attenuation of scalar fluxes measured with displaced sensors, EGS-AGU-EUG Joint Assembly, Nice, France, April 6-11.

Kang, H. S. and S. Y. Hong, 2008: An assessment of the land surface parameters on the simulated regional climate circulations: The 1997 and 1998 east Asian summer monsoon cases. J. Geophys. Res., 113, D15121, doi: 10.1029/2007JD009499. [Link]

Kotani, A. and M. Sugita, 2005: Seasonal variation of surface fluxes and scalar roughness of suburban land covers. Agric. For. Meteorol., 135, 1-21, doi: 10.1016/j. agrformet.2005.09.012. [Link]

Kubota, A. and M. Sugita, 1994: Radiometrically determined skin temperature and scalar roughness to estimate surface heat flux. Part I: Parameterization of radiometric scalar roughness. Bound.-Layer Meteor., 69, 397-416, doi: 10.1007/BF00718127. [Link]

Lhomme, J. P., A. Chehbouni, and B. Monteny, 2000: Sensible heat flux-radiometric surface temperature relationship over sparse vegetation: Parameterizing $B^{-1}$. Bound.-Layer Meteor., 97, 431-457, doi: 10.1023/A:1 002786402695. [Link]

Lo, A. K.-F., 1996: On the role of roughness lengths in flux parameterizations of boundary-layer models. Bound.Layer Meteor., 80, 403-413, doi: 10.1007/BF001194 25. [Link]

Mahrt, L. and D. Vickers, 2005: Moisture fluxes over snow with and without protruding vegetation. Q.J. R. Meteorol. Soc., 131, 1251-1270, doi: 10.1256/qj.04.66. [Link]

Mauder, M. and T. Foken, 2004: Documentation and Instruction Manual of the Eddy Covariance Software Package TK2. In: Abt. Mikrometeorologie (Ed.), University Bayreuth, Bayreuth, $45 \mathrm{pp}$.

Moriwaki, R. and M. Kanda, 2006: Scalar roughness parameters for a suburban area. J. Meteorol. Soc. Jpn., 84, 1063-1071.

Noilhan, J. and S. Planton, 1989: A simple parameterization of land surface processes for meteorological models. Mon. Weather Rev., 117, 536-549, doi: 10.1175/15200493(1989)117<0536:ASPOLS>2.0.CO;2. [Link]

Oncley, S. P., T. Foken, R. Vogt, W. Kohsiek, H. A. R. DeBruin, C. Bernhofer, A. Christen, E. van Gorsel, D. 
Grantz, C. Feigenwinter, I. Lehner, C. Liebethal, H. Liu, M. Mauder, A. Pitacco, L. Ribeiro, and T. Weidinger, 2007: The energy balance experiment EBEX-2000. Part I: Overview and energy balance. Bound.-Layer Meteor., 123, 1-28, doi: 10.1007/s10546-007-9161-1. [Link]

Park, S. J., S. U. Park, C. H. Ho, and L. Mahrt, 2009: Fluxgradient relationship of water vapor in the surface layer obtained from CASES-99 experiment. J. Geophys. Res., 114, D08115, doi: 10.1029/2008jd011157. [Link]

Qualls, R. and T. Hopson, 1998: Combined use of vegetation density, friction velocity, and solar elevation to parameterize the scalar roughness for sensible heat. $J$. Atmos. Sci., 55, 1198-1208.

Schotanus, P., F. T. M. Nieuwstadt, and H. A. R. DeBruin, 1983: Temperature measurement with a sonic anemometer and its application to heat and moisture fluxes. Bound.-Layer Meteor., 26, 81-93, doi: 10.1007/ BF00164332. [Link]

Smeets, C. J. P. P. and M. R. van denBroeke, 2008: The parameterisation of scalar transfer over rough ice. Bound.-Layer Meteor., 128, 339-355, doi: 10.1007/s1 0546-008-9292-z. [Link]

Sun, J., 1999: Diurnal variations of thermal roughness height over a grassland. Bound.-Layer Meteor., 92, 407-427, doi: 10.1023/A:1002071421362. [Link]

Tsuang, B. J., 2004: Data archive strategy for computing the long-term means of nonlinear functions in geophysical problems. Clim. Res., 27, 225-230.

Van Dijk, A., W. Kohsiek, and H. A. R. de Bruin, 2003: Oxygen sensitivity of krypton and Lyman- $\alpha$ hygrometers. J. Atmos. Ocean. Technol., 20, 143-151, doi: 10. 1175/1520-0426(2003)020<0143:OSOKAL>2.0.
$\mathrm{CO}$;2. [Link]

Verhoef, A., H. A. R. de Bruin, and B. J. J. M. van den Hurk, 1997: Some practical notes on the parameter $\mathrm{kB}^{-1}$ for sparse vegetation. J. Appl. Meteorol., 36, 560572, doi: 10.1175/1520-0450(1997)036<0560:SPNOT P>2.0.CO;2. [Link]

Vickers, D. and L. Mahrt, 2006: Evaluation of the air-sea bulk formula and sea-surface temperature variability from observations. J. Geophys. Res., 111, C05002, doi: 10.1029/2005JC003323. [Link]

Webb, E. K., G. I. Pearman, and R. Leuning, 1980: Correction of flux measurements for density effects due to heat and water vapour transfer. Q.J.R. Meteorol. Soc., 106, 85-100, doi: 10.1002/qj.49710644707. [Link]

Yang, K., T. Koike, H. Ishikawa, J. Kim, X. Li, H. Liu, S. Liu, Y. Ma, and J. Wang, 2008: Turbulent flux transfer over bare-soil surfaces: Characteristics and parameterization. J. Appl. Meteorol. Climatol., 47, 276-290, doi: 10.1175/2007JAMC1547.1. [Link]

Zeng, X. and R. E. Dickinson, 1998: Effect of surface sublayer on surface skin temperature and fluxes. J. Climate, 11, 537-550, doi: 10.1175/1520-0442(1998)011 $<0537$ :EOSSOS >2.0.CO;2. [Link]

Zilitinkevich, S. S., 1995: Non-local turbulent transport: Pollution dispersion aspects of coherent structure of convective flows. In: Power, H., N. Moussiopoulos, and C.A. Brebbia (Eds.), Air Pollution III - Volume 1, Air Pollution Theory and Simulation, Computational Mechanics Publications, Southampton Boston, 53-60.

Zilitinkevich, S. S., A. A. Grachev, and C. W. Fairall, 2001: Scaling reasoning and field data on the sea surface roughness lengths for scalars. J. Atmos. Sci., 58, 320325, doi: 10.1175/1520-0469(2001)058<0320:NACR $\mathrm{AF}>2.0 . \mathrm{CO}$;2. [Link] 